\title{
A Survey of the Mixed Use of He/She for Chinese Freshmen in English Majors
}

\author{
Yixuan Liang ${ }^{1} \&$ Fang Guo ${ }^{1}$ \\ ${ }^{1}$ School of Foreign Languages, North China Electric Power University, Beijing, China \\ Correspondence: Yixuan Liang, School of Foreign Languages, North China Electric Power University, Beijing, \\ China. E-mail: 745816995@qq.com
}

Received: November 2, 2020

Accepted: December 7, 2020

Online Published: December 16, 2020

doi:10.5539/ijel.v11n1p166

URL: https://doi.org/10.5539/ijel.v11n1p166

\begin{abstract}
The mixed use of he/she in oral English is a hot topic in the field of second language acquisition in the past decades and the related study is numerous. However, there are few studies on the misuse of the two pronouns in oral English for English majors in Chinese universities. This study aims to explore the current situation and characteristics of he/she misuse in oral English of Chinese freshmen majoring in English and analyze the factors that cause the misuse, so as to arouse the learners' awareness of the error. This study focuses on two research questions: (1) What are the characteristics of he/she misuse in spoken English of Chinese freshmen majoring in English? (2) What are the reasons for the misuse? Based on the selected spoken language materials, this study explores the mixing types and error rate of he/she and analyzes the characteristics of the misuse through data. Through the questionnaire, this thesis study investigates the causes of the misuse. It is found that the mixed use of pronoun he/she is serious in the spoken language of English major freshmen, especially the misuse of "she" into "he". The factors that cause the misuse are complex, involving mother tongue, attention distribution and working memory, pronunciation relationship, transfer of training, and social environment and personal factors, among which the analysis from articulatory phonetics deserves more attention.
\end{abstract}

Keywords: the misuse of he/she, English major learners, spoken English, articulatory phonetics

\section{Introduction}

As the most widely used language in the world, English is bound to become the primary choice for international communication. It is well known that English learning is a comprehensive grasp of listening, speaking, reading, and writing. In addition to mastering vocabulary and grammar, the oral expression is also essential. However, on account of the differences between Chinese and English cultures, language habits, and individual thinking, many errors in second language expressions are appearing and inevitable.

Pronouns refer to either a noun that has already been mentioned or to a noun that does not need to be named specifically. The most common pronouns are the personal pronouns, which refer to the person or people speaking or writing (first person), the person or people being spoken to (second person), or other people or things (third person). And "he" and "she" are the single form of the third person. In various countries, second-language learners show no consistency in the mixed use of he/she in spoken language. Chan and Wong (2001) demonstrate that in the conversion of Malaysian and English, people frequently mix third-person pronouns. According to Antón-Méndez (2010a), French speakers are less likely to make gender errors, while Spanish speakers are more likely to make that. What's more, Chen (2013) points out Korean speakers tend to take the neutral strategy than to use the specific male or female pronouns due to gender discrimination for third singular pronouns. In Japan, Kamimura and Oi (2001) report that the English learners have difficulty in taking the third-person point of view to write a story compared with taking the first-person point of view.

This thesis is aimed to survey the mixed use of he/she for freshmen in English majors. Relevant research of speech materials and a questionnaire will be conducted. If personal pronouns are mixed, it will easily contribute to misunderstandings among people. Only if reducing the error rate of misuse, can people avoid such the above-mentioned trouble. At the same time, it is also helpful for the improvement of the language level of second language learners. 


\section{Literature Review}

Levelt (1989), drawing up the "speaker blueprint", joins other researchers in slicing the production process into three main independent components: conceptualization, formulation, and articulation. Conceptualization refers to the preparation stage of message generation of language, including monitoring the process of forming the language; formulation refers to the construction of a fully specified linguistic message, involving grammatical encoding as well as phonological encoding; and articulation converts this abstract message into motor commands to the muscles. The three components are hierarchically ordered, and then the output from the upper stage can serve as the input toward the lower stage, which provides a theoretical basis for the study of the mixed use of the pronouns "he" and "she".

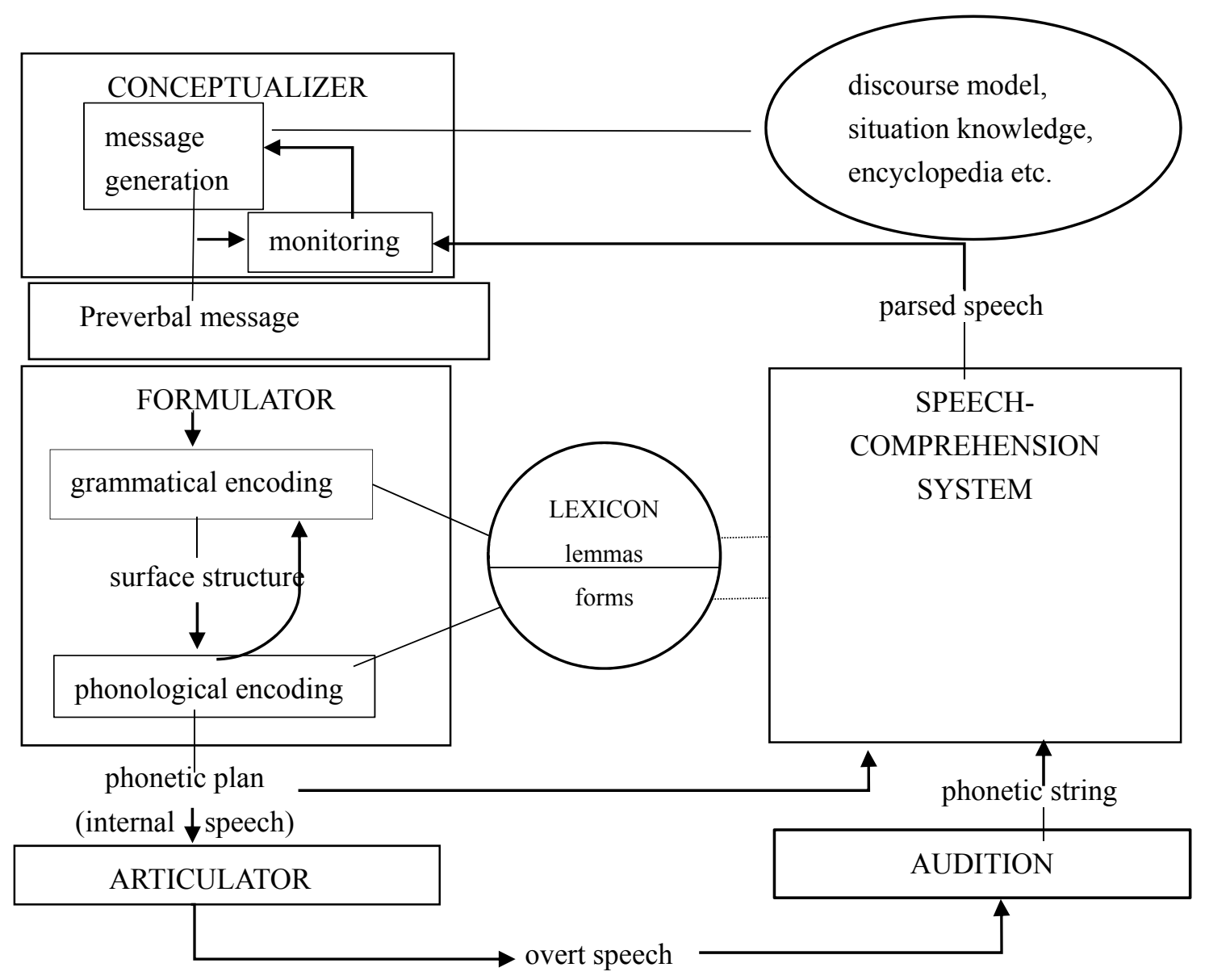

Figure 1. Speaker blueprint-Levelt (1989)

Antón-Méndez (2010a) holds the source of the error must be in the message generation stage of conceptualization. In a subsequent study by Antón-Méndez (2010b), it demonstrates that the gender error on his/her is due to the negative transfer of the mother tongue. As for Dong and $\mathrm{Li}$ (2011), the results show that the mixed use of pronouns he/she by Chinese EFL (English as a Foreign Language) learners is not a choice error in the form, but the lack of gender information of pronouns in the message generation stage. These researches are based on the message generation theory. Many other aspects on explaining the misuse phenomenon have been conducted like working memory and distance (Clark \& Sengul, 1979), image-level theory (Tao, 2003), gender discrimination in language (Jiang, 2008) and basic level categories (Zhao, 2011).

However, very few scholars study it from the perspective of phonetics. According to Wei (2003), there are four initial consonants with retroflex sounds in Mandarin: $\mathrm{Zh}, \mathrm{Ch}, \mathrm{Sh}, \mathrm{R}$ (among them, $\mathrm{Zh}$ and $\mathrm{Ch}$ are both affricates and aspirated). There is no initial retroflex sound in Zhuang language, so it is often read as other initiatives in Mandarin. Part of the Chinese show difficulty in articulating retroflex sound. Keating (1991) mentions that a 
somewhat different kind of retroflex fricative is found in Chinese and that is "sh". There exits similarity in articulation between / $/$ / in English and "sh" in Chinese. It is noteworthy that this oral misuse of Chinese English majors can be analyzed through articulatory phonetics theory.

\section{Methodology}

This part will involve research questions, research methods, and data collection. The methods of research cover two ways - a corpus survey as well as a questionnaire survey so as to resolve the two research questions.

\subsection{Research Questions}

Although scholars at home and abroad have done some research on the confusion of "he" and "she", few people study it in terms of freshmen of English major. The main problems that this study aims to probe into are as follows:

(1) What are the characteristics of he/she misuse in spoken English of Chinese freshmen majoring in English?

(2) What are the reasons for the misuse?

\subsection{Research Methods}

In order to answer the above two questions, two methods are adopted on the strength of the actual situation and specific acquirement of this study. They are:

\section{1) Corpus Survey Method}

This corpus comes from the audios of the final oral English test of the 2019 grade freshmen in the school of foreign languages of North China Electric Power University. The foreign teacher sets questions involving the daily life around students, personal values, and other contents. The students randomly select the questions and are given two minutes to prepare for the speech. The average duration of each audio is 3 minutes, with 61 recorded.

\section{2) Questionnaire Survey Method}

This questionnaire adopts the setup of Chinese questions and is designed for all English majors. There are 14 questions in total. The first three questions are to record the subjects' school, major, and grade. Questions 4 to 9 , 11, and 13 are in the form of multiple choices. The possible causes of misuse phenomenon are analyzed from different perspectives. Question 10 is to make statistics on the number of people whether there is mixed-use, question 12 is to make statistics on the frequency of mixed-use of the third person nominative pronouns, and the last question is to explore and supplement the causes of mixed-use in the form of short answer questions.

\subsection{Data Collection}

In this section, it contains corpus data collection and questionnaire data collection. Hence, collection methods, data size, and data requirements will be presented.

\section{1) Corpus Data Collection}

After excluding all these audio texts that cannot confirm the gender of antecedent (for example the doctor), the rest are composed into sub-corpus M1, and M1 has 52 copies. Subsequently, the requirement is to select those sentences with the wrong gender from M1 to form sub-corpus M2, which has 31 copies.

In line with the statistical method of Dong Yanping and Jia Tingting (2011), the error rate is calculated according to the percentage system, and the following three values are calculated: 1) the frequency of each singular third-person pronoun in M2 (such as heW and sheW); 2) the frequency of each pronoun in M1 (such as heT and sheT); 3) the error rate of each pronoun. This survey defines "he-error rate" as "he should be used but is misused into she". The formula for calculating the error rate of the pronoun "he": sheW / (heT-heW + sheW), and the formula for calculating the error rate of "she": heW / (sheT-sheW +heW).

\section{2) Questionnaire Data Collection}

There are 187 questionnaires and 185 are valid ones. Two of them are from students majoring in Japanese and Pedagogy, which is not suitable for the requirement of the study. According to the data, the majority of the subjects are from North China Electric Power University, a small part is from Dalian Foreign Studies University and Yan Shan University and other universities, and all majors are English or Translation. Students from grade one to grade four all participated in the survey, and the participation rate of each grade was relatively average.

\section{Analysis and Discussion}

Analysis and discussion are the main part of the whole thesis, so based on the two-research method, it will be 
fallen into two sections-corpus-based analysis and questionnaire-based analysis.

\subsection{Corpus-Based Analysis}

In this section, corpus data are supposed to be analyzed and discussed in detail so that a clear situation of the mixed use "he" and "she" can be grasped.

\subsubsection{Statistical Data from Corpus}

Through the statistical method of Dong Yanping and Jia Tingting (2011), sub-corpus M1 and sub-corpus M2 are established, which helps count the numbers of correct pronouns and the misuse ones up, and then the error rate of one pronoun can be calculated. For instance, the formula for calculating the error rate of the pronoun "he": sheW / (heT-heW + sheW). See Table 1 for statistical results:

Table 1. The correct pronoun and its error rate (and original frequency)

\begin{tabular}{llllll}
\hline & Nominative Case & Objective Case & Possessive Case & Reflexive Pronoun & Average \\
\hline Positive & he & him & his & himself & \\
& 2.70 & 0.00 & 28.57 & 0.00 & 5.26 \\
\multirow{4}{*}{ Negative } & $(1 / 37)$ & $(0 / 12)$ & $(2 / 7)$ & $(0 / 1)$ & $(3 / 57)$ \\
& she & her & her & herself & \\
& 28.57 & 12.50 & 3.33 & 0.00 & 25.56 \\
Average & $(16 / 56)$ & $(2 / 16)$ & $(5 / 15)$ & $(0 / 3)$ & $(23 / 90)$ \\
& 18.28 & 7.14 & 31.82 & 0.00 & 17.69 \\
& $(17 / 93)$ & $(2 / 28)$ & $(7 / 22)$ & $(0 / 4)$ & $(26 / 147)$ \\
\hline
\end{tabular}

(1) Negative antecedents appear more often than positive antecedents. In $25.56 \%$ cases, the positive pronoun (he, him, his, himself) was mistakenly used to replace the negative antecedents, while in $5.26 \%$ cases, the negative pronoun (she, her, her, herself) was used to replace the positive ones.

(2) The nominative case and the possessive case are more likely to be mixed (18.28\% vs $31.82 \%)$; the objective case and reflexive pronoun are less likely to be mixed $(7.14 \%$ vs $0.00 \%)$. Among them, the error rate of possessive "her" is the highest (i.e., when people should have said "her", they express into "his"), which is $33.33 \%$; the error rate of reflexive pronoun is the lowest, which is $0.00 \%$.

\subsubsection{Situations for Misuse}

According to the survey results, the following misuse situation can be described:

(1) The gender confusion of the third person singular pronouns is very serious in oral English. In the 52 spoken texts involved in this study, there are different degrees of gender misuse of pronouns.

(2) There are some rules for the gender confusion of the third person singular pronouns. Students are always more inclined to misuse negative pronouns, i.e., they use positive pronouns where they should have used negative pronouns (e.g., When students express "she", they speak out "he").

It should be noted that the actual error rate of third-person pronoun mixing should be higher than that reported here because this survey excludes all texts that are difficult to judge the gender of antecedents. For instance, the example (the doctor) mentioned at the beginning of the article is excluded. This antecedent here is a noun without gender mark in English, and the use of context pronouns also makes it impossible to judge whether the doctor is a man or a woman. Such texts tend to have a higher error rate.

Therefore, from Table 1, we can see that the mixed use of nominative he/she in oral English by freshmen in English major is severe, which is still worthy of attention by learners and researchers.

\subsection{Questionnaire-Based Analysis}

In this section, the questions in the questionnaire will be fully discussed and a mass of data will be displayed by graphs.

\subsubsection{Statistical Data from Questionnaire}

As mentioned above, the first four questions are about the statistics of background information in the survey. The rest is mainly about the investigation of the reasons for the mixed use in he/she oral English and the discussion.

Question 4: Choose your gender

A: Male 


\section{B: Female}

Question 4 is to make statistics on the gender of 185 respondents. After integrating with question 10, this question is to explore whether gender differences will confuse the pronouns of the third person nominative.

Table 2. The choice of gender and its error rate

\begin{tabular}{lllll}
\hline & Total Number & Using Wrongly & Using Correctly & Error Rate \\
\hline Male & 16 & 16 & 0 & $100 \%$ \\
Female & 169 & 162 & 7 & $95.68 \%$ \\
\hline
\end{tabular}

From Table 2, we can see that 16 men and 169 women participated in the survey. The mixed-use rate is $100 \%$ in males and $95.86 \%$ in females. Nevertheless, for the probability of mixed-use between the two has little difference, it cannot be well judged whether the gender difference can affect the mixed use of he/she in oral English.

Question 5: How long have you been studying English?

Question 5 is to make statistics on the years of learners' learning English time. After the integration with question 10, question 5 is to explore whether the number of years of second language learners' learning time will affect the misuse.

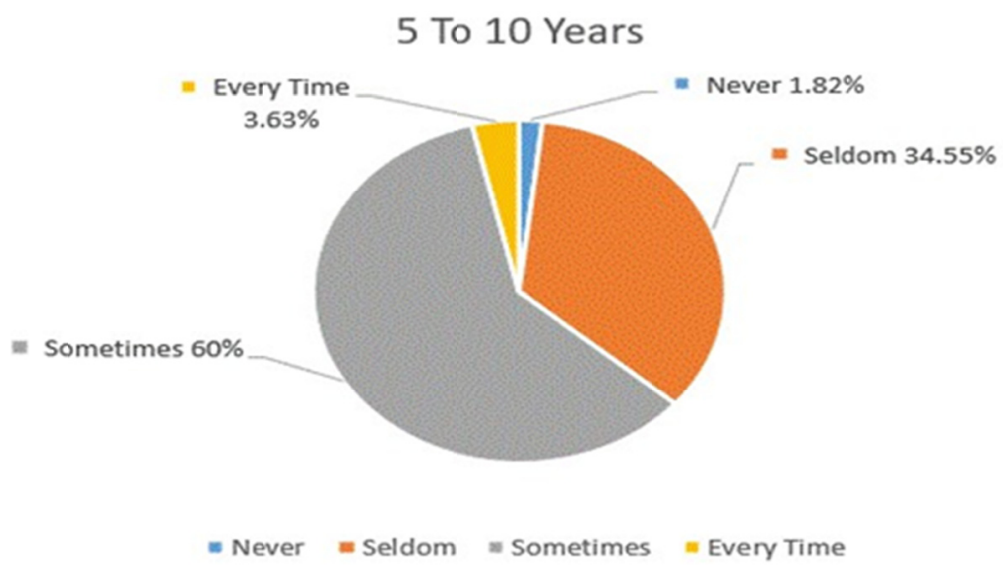

Figure 2. Question 5.1-Studying Years from 5 to 10

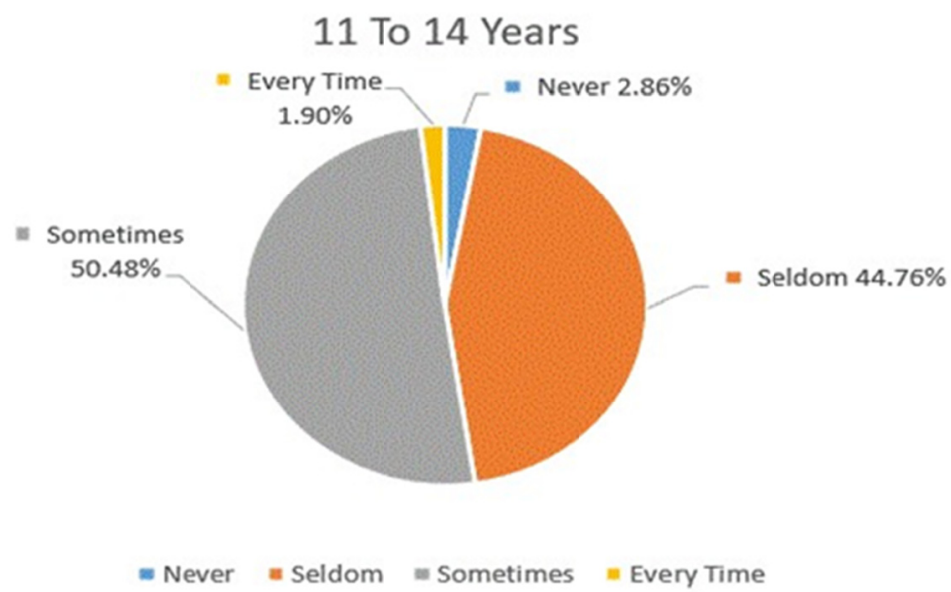

Figure 3. Question 5.2-Studying Years from 11 to 14) 


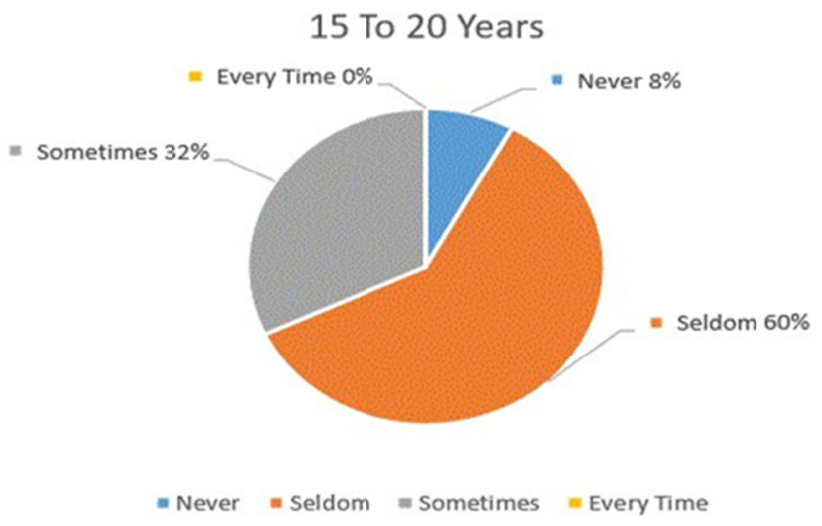

Figure 4. Question 5.3-Studying Years from 15 to 20

According to the respondents, they have studied English from six to twenty years. In this regard, the thesis divides it into three categories, namely 5-10 years, 11-14 years, and 15-20 years. Based on the frequency of mixing, we can divide it into "never", "seldom", "sometimes", and "always". In the group of 5-10 years of study, the probability of "never" mixed-use is $1.82 \%$, the probability of "seldom" occurrence is $34.55 \%$, "sometimes" occurrence is $60 \%$, and the probability of "always" occurrence is $3.63 \%$; in the group of 11-14 years of study, the probability of "never" mixed-use is $2.86 \%$, "seldom" $44.76 \%$, "sometimes" $50.48 \%$, and "always" $1.90 \%$; in the group of 11-14 years of study, the probability of "never" mixed-use is $2.86 \%$, "seldom" $44.76 \%$, "sometimes" $50.48 \%$, and "always" $1.90 \%$; in the group of $15-20$ years of study, the probability of "never" mixed-use is $8 \%$, "seldom" $60 \%$, "sometimes" $32 \%$, and "always" $0 \%$.

Through the above analysis, we can see that the longer the learning time is, the less likely it is to make mistakes in oral English, and vice versa.

Question 6: Have you attended a one-to-one/one-to-many private (foreign/Chinese) oral English training course before going to college?

A: Yes

B: No

The purpose of question 6 is to explore whether there has been any special oral training before entering the university and systematically learning English, especially before practicing oral English. If people have received the corresponding training before entering the university, it may reduce the incidence of oral errors.

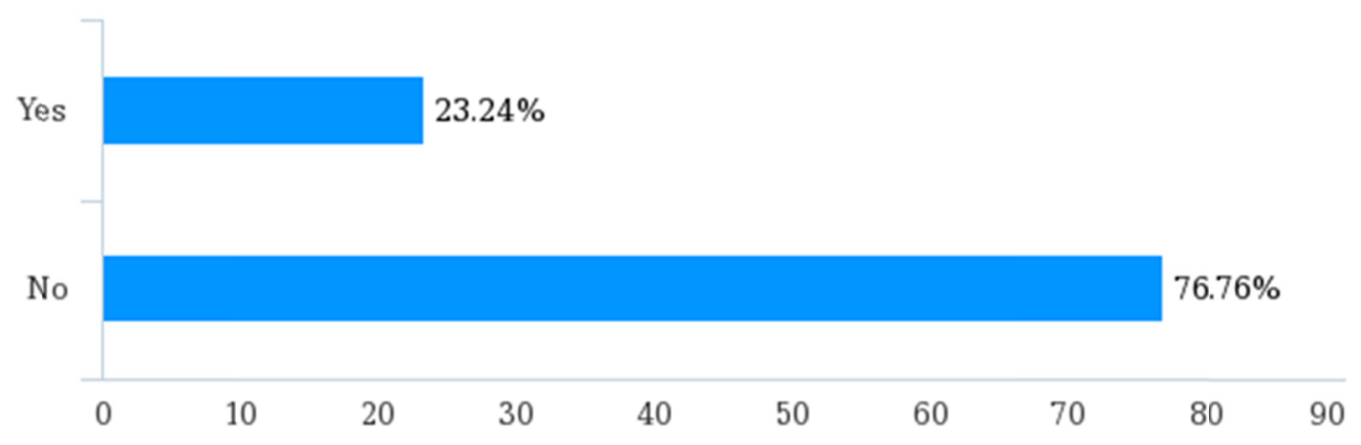

Figure 5. Question 6-The Ratio of Attending Private Oral Training

According to the data, $23.24 \%$ of the students had received the corresponding private oral training before entering the university, while $76.76 \%$ of the students had not received the type of training. Through this chart, we know that most people have not received professional oral training before entering university, only less than $1 / 4$ of the students have received it. 
Question 7: How often do you practice speaking English?
A: Every Day
B: Often
C: Sometimes
D: Seldom

The purpose of this question is to investigate the practice of oral English of English majors and make corresponding judgments according to the frequency of practice. Generally speaking, the more frequently people practice speaking, the higher their proficiency, and the lower their probability of making mistakes.

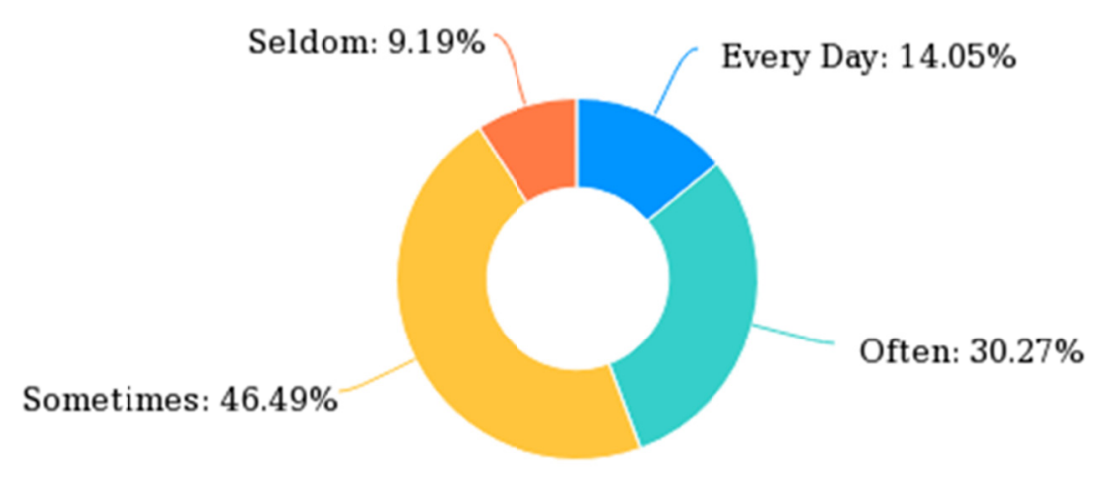

Figure 6. Question 7-The Ratio of Practicing Speaking English

According to the data, $14.05 \%$ of the students practice oral English every day, $30.27 \%$ of the students often practice oral English, and $46.49 \%$ of the students sometimes practice oral English. However, there are still $9.19 \%$ of the students who almost do not carry out too much oral training in daily life. From this chart, we can see that most of the students do corresponding oral training in their study and life, and only less than $10 \%$ of the students have little practice.

Question 8: Do you feel nervous or anxious when speaking English?

A: Yes

B: No

Is it because of the emotional factors that people feel anxious and nervous when they speak English? That is what this question wants to figure out. To some extent, this kind of negative emotions can affect the occurrence of errors in oral expression.

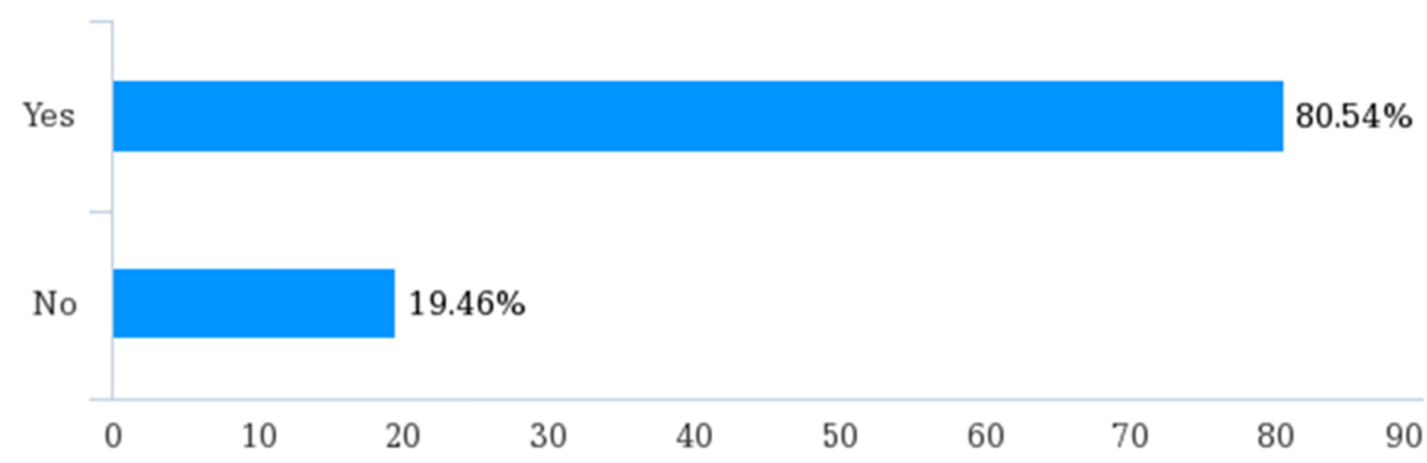

Figure 7. Question 8-The Ratio of Affecting by Negative Emotions) 
According to the data, $80.54 \%$ of the students have anxiety and tension in English communication while $19.46 \%$ of the students do not have anxiety and tension in oral expression. The ratio difference between the two is large and obvious, so it can be concluded that the emotional factors might lead to 2 the misuse of he/she.

Question 9: In oral English, do you pay more attention to the transmission of meaning or the form of language?

A: Meaning

B: Form

This question is to analyze the causes of mixed-use from the perspective of resource allocation. When people express themselves, do they pay more attention to the expression of the meaning of the whole sentence or the use of personal pronouns? If people pay more attention to the expression of the overall meaning of the sentence, they may ignore the use of form to some extent, for example, the use of third-person pronouns.

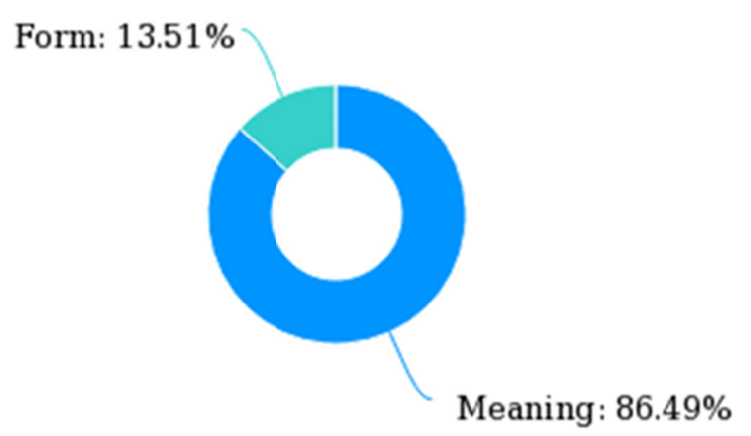

Figure 8. Question 9-The Ratio of Emphasizing on Form or Meaning

According to the survey data, $86.49 \%$ of the students pay more attention to the expression of the overall meaning, while only $13.51 \%$ of the students pay attention to the use of form. Through the comparison, we can see that students pay more attention to the transmission in the overall sense, and ignore the use of form to a certain extent.

Question 10: Do you think you will misuse he/she in spoken English? (He is referred to as she, or she is referred to as he)
A: Every Time
B: Sometimes
C: Seldom
D: Never

Question 10 is to find out whether there is a mixed-use of he/she in oral expression among 185 students in the survey. The purpose of this study is to figure out whether English majors also mix pronouns in the third person nominative.

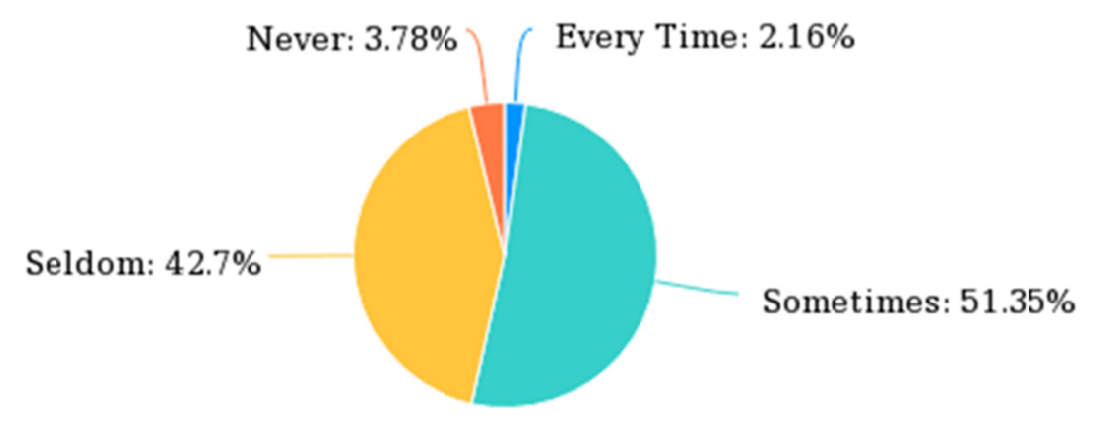

Figure 9. Question 10-The Ratio of the Misuse Frequency 
According to the data, $2.16 \%$ of 185 students make mistakes every time in oral expression, $51.35 \%$ sometimes mix them up, $42.7 \%$ of them say they rarely mix them up, and finally only 3.78 students say they never use them wrongly. It can be seen that more than $95 \%$ of the people have mixed the use of he/she in different degrees, and merely less than $5 \%$ of the people say that there is no misuse.

Question 11: Have you ever noticed that he/she is mixed in the voice teaching materials or the teacher's expressions?
A: Yes
B: No

This topic is to explore the reasons from the perspective of training transfer. In the process of learning English, more or fewer people will find some mistakes in the textbook or in the teacher's expression. Some may be grammatical errors while others may be structural errors. Will these mistakes affect students' oral output to some degree? This also needs attention.

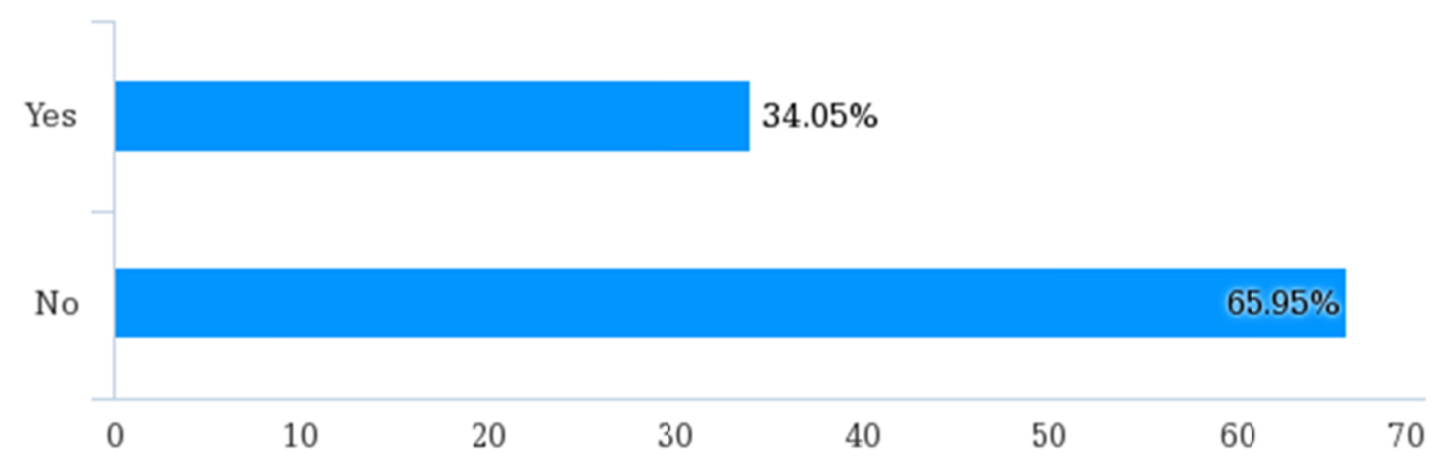

Figure 10. Question 11-The Ratio of Affecting by Text Materials and Teachers' Expressions

According to survey data, $34.05 \%$ of the students have ever found he/she misuse in their textbooks or teacher's expressions, while $65.96 \%$ of the students have never found it in the previous English learning. From this chart, we can see that the probability of mistakes in the textbooks and teachers' oral expressions is not extremely high, but this still happens. So, whether they will influence the students' oral expression subtly, there is also a certain possibility.

Question 12: Who does he/she use more frequently in the actual oral practice in the classroom/out of class?
A: he
B: she

This question is to examine the frequency of students' choice in he/she from the perspective of and transfer of training as well as psychological mechanism. Provided that a third person subject pronoun is used too much, will it form a fixed mindset, which will lead to the subconscious choice of the word in oral expression, resulting in misuse?

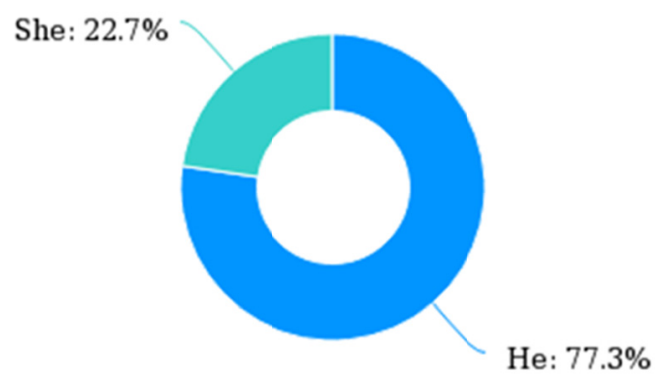

Figure 11. Question 12-The Ratio of Using He or She 
According to the data survey, the use frequency of "he" accounts for $77.3 \%$, while that of "she" only accounts for $22.7 \%$. It can be seen that people prefer to use the third person positive pronoun in their daily expression, which also verifies the conclusion of the previous corpus survey (Students are always more inclined to misuse the negative pronoun, that is, they use the positive pronoun where they should have used the negative pronoun).

Question 13: Do you pay attention to the use when speaking he/she in spoken language?

A: Yes

B: No

The purpose of this question is to explore whether the choice of pronouns under the condition of intentional attention will affect the mixed use of he/she from the perspective of the monitoring strategy.

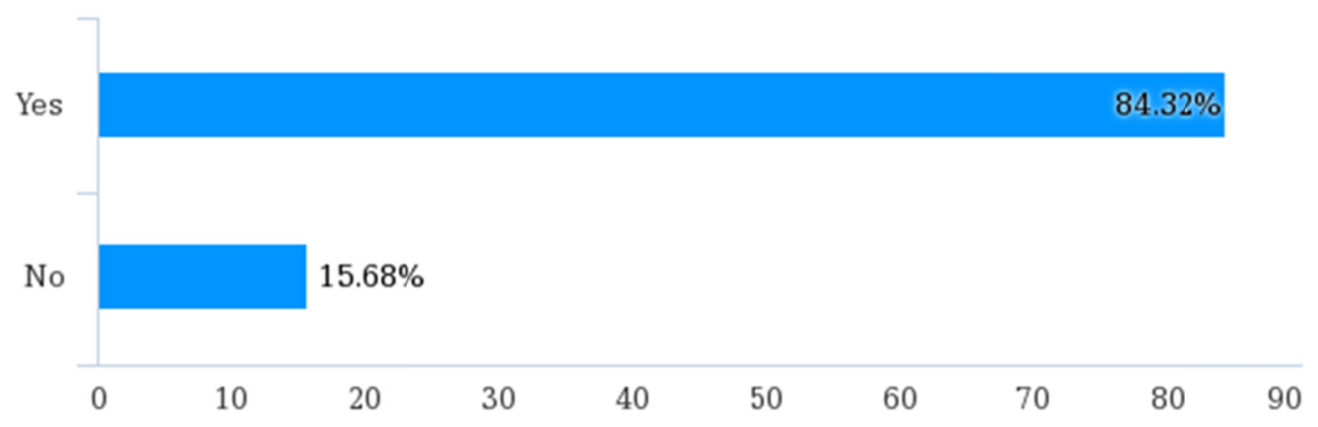

Figure 12. Question 13-The Ratio of Intentional Attention

According to the data, $84.32 \%$ of the students would attach importance to the use of third-person nominative pronouns, while $15.68 \%$ would not care about their use. From this chart, we can see that there are still quite a few students who will pay attention to the choice of he/she in oral output. But in this case, there are still many students mixed-use phenomenon. Perhaps there are errors in the process of monitoring, or the effect of monitoring strategy is not effective, resulting in the error rate has been at a high level.

Question 14: In your opinion, what are the reasons for the mixed use of he/she in spoken English?

This question has been set up as an open and short answer one, to acquire people's views on the misuse of "he" and "she" in oral English. In the 185 questionnaires received, almost every student gives their reasons for mixing. Through the written summary, there are the following points of view:

(1) Influenced by native language habits, there is no difference in pronunciation between “他” and “她” in Chinese, and it is easy to ignore the process of sentence formation when people speaking English.

(2) When talking with people, I am nervous and not confident. Sometimes I take he/she in my mind, but I speak out the opposite one.

(3) In China, the social status of men is far higher than that of women, so people use "he" to cover all people.

(4) I think most people use "he" to describe girls accidentally. It's probably because everyone makes sentences with "he" in most cases from childhood. Many personal pronouns appearing in textbooks are male, which are used too often.

(5) It may be influenced by the prominence of the former noun reference.

(6) In real-time conversation, people are easy to ignore the third person single pronouns because of considering the grammatical structure of the sentence subject.

(7) I do not care about the gender of the subject when I express.

(8) I am unskilled in mastering English.

(9) When expressing, we should pay more attention to the expression of the meaning of the whole sentence rather than the use of personal pronouns.

(10) Thinking is not agile enough to form English thinking in this respect.

(11) Say too much about one pronoun, then form a kind of thinking set, which becomes a subconscious habit.

(12) Because we express too fast to respond instantly. 
(13) Too little practice, if you speak too much, you will remember more clearly and form a memory

(14) Among languages, there are nouns of both genders (such as various occupations). People are accustomed to using "he" to refer to those kinds of nouns.

(15) Influenced by talkers' environment, their habitual address choices will be affected by their friends' gender.

(16) Influenced by their own gender, they prefer to use the same-sex third person.

(17) It may be influenced by the pronunciation relationship between "he" and "she".

(18) Because of too many contents needing express, people forget the subject gender, which affects the use of pronoun.

\subsubsection{Reasons for Misuse}

The explanations given by the students in the questionnaire are simple, but they provide the most authentic first-hand information for us to accurately explain the causes of he/she mixed-use in oral English of students in English majors. On a basis of relevant linguistic theories, this section analyzes the reasons of the mixture of Chinese EFL learners' third person nominative pronouns.

\section{(1) Affected by Mother Tongue}

When it comes to the reasons for the mixed use of the third person nominative pronouns, it is greatly influenced by mother tongue, like answer (1). First of all, message generation theory has to be mentioned. According to the speech production model of Levelt (1989), we know that language message generation occurs in the conceptualizer. There are differences in information needs between the two languages. “他” and “她” in Chinese do not differ in pronunciation; The third person nominative pronouns in English have different pronunciations and meanings. Bilinguals may be able to prepare language information according to L1 when speaking L2 (for example, no pronoun gender information is required). Speaking L2 may have no grammatical problems, but its content is abnormal (for example, pronoun gender error) which affects the wrong use of pronoun he/she.

Besides, when people gain new knowledge, they will certainly involve the transfer of old knowledge. If the old knowledge promotes the learning of new knowledge, it is called positive transfer; otherwise, if the old knowledge hinders the learning of new knowledge, it becomes negative transfer. Antón-Méndez (2010b) holds even high-level bilinguals are influenced by mother tongue transfer in second language speaking. For Chinese English learners, the negative transfer of their mother tongue often affects their second language learning. English and Chinese belong to different language families. They are quite various in phonetics, vocabulary, grammatical structure and so on. Therefore, in the process of constructing learners' interlanguage, there are many components of "negative transfer" of their mother tongue. As for the third person single pronoun, in Chinese, “他” and “她” are different in writing, but there is no difference in pronunciation; in English, there are obvious varieties in writing and pronunciation between "he" and "she". Hence, in oral communication, the learners are easily influenced by Chinese and make mistakes frequently.

\section{(2) Affected by Attention Distribution and Working Memory}

Through answers (5)6(7)(9), we can conclude that attention distribution performs a certain function in he/she mixing. Under Tao (2003), he emphasizes the mixed use is due to meaning transmission, focusing on the overall content of transmission and the prominence of subject and predicate. In terms of this questionnaire survey, most of the English learners pay much attention to the expression of the overall meaning of sentences in the process of communication, thus ignoring the use of sentence structure and form. At the same time, some students point out that the lack of prominence of the antecedents leads to the wrong choice of nominative pronouns.

Of course, answer (18) also indicates that working memory has a related effect on the mixing of "he" and "she". Clark and Sengul (1979) finds that the greater the distance between anaphora and antecedent, the longer time it takes to understand. This also suggests that the longer the distance between anaphora and antecedent, the more requirements for working memory. Therefore, if the distance between personal pronouns and reference words is too far, for learners with poor working memory ability, they are intensely easy to forget the reference words when expressing, thus affecting the use of personal pronouns.

\section{(3) Affected by Pronunciation Relationship}

In English, the pronunciation of "he" is /hi:/, and "she" is / $/ \mathrm{i}: /$. Although the consonants of the two words are different, they both have the same vowel pronunciation-the long vowel /i:/. Therefore, when the speaker is faced with the choice of "he" and "she", it is very easy to misuse because of the close relationship between pronunciation. 
However, although the two words have similarities in pronunciation, their consonant pronunciation is different, which also causes the misuse of pronoun. For many Chinese people, when they speak Mandarin, there is no distinction between blade-alveolar and retroflex, that is, the initial "s" and the initial "sh". Most people tend to pronounce "sh" as "s", so it is difficult for Chinese students to pronounce "she" well. According to IPA (International Phonetic Alphabet), when consonant $/ \mathrm{J} /$ is pronounced, the tongue end is close to the back of the gingiva, the tongue body is raised close to the upper jaw, the lips are slightly rounded and slightly protruded, and friction sounds are formed when air flow passes through. It's a voiceless consonant and the vocal cords don't vibrate. Pan (2012) holds that the Chinese initial "sh" is a tip to gingival affricate (abbreviated to as post tip affricate), which is similar to pronunciation of $/ \mathrm{J} /$. Hence, we can deduce that Chinese students also have difficulty in pronunciation of $/ \mathrm{S} /$. According to Wei (2003), though people are easy to pronounce " $\mathrm{H}$ " as " $\mathrm{F}$ " when the initial " $\mathrm{H}$ " and vowel " $\mathrm{U}$ " is spelled together in some parts of southern China, there is no misreading when " $\mathrm{H}$ " is spelled with other vowels. So, there is no big problem for Chinese second language learners to pronounce consonant $/ \mathrm{h} /$.

From what have been mentioned above, students are more inclined to "he" in the choice of "he" and "she".

(4) Affected by Transfer of Training

Zheng (2011) points out that, on the one hand, transfer of training refers to the inappropriate teaching in foreign language, which causes learners to generate incorrect understanding of some language points and grammar rules of the target language. These misunderstandings are often deep-rooted due to the initial stage of learners' learning, that is, the period when language habits are formed; on the other hand, language improper use of speech materials can also lead to training transfer. In the questionnaire survey, answer (4)(8)(11)(13) argues that people usually take this problem less seriously when choosing words and making sentences, oral practice is too little, and "he" has more opportunities to be used in the teaching materials and teachers' expressions. All of these belong to transfer of training that contributes to the misuse of "he" and "she".

\section{(5) Affected by Social Environment and Personal Factors}

From the perspective of history, there has been the idea that men are superior to women since ancient times. On this basis, there will be gender discrimination in language. According to Yu (2015), all specification is designed for men. The male language is the standard while the female language is only a subsidiary or a variant. "he" stands for men, "she" stands for women, and people are more inclined to use "he". Therefore, sexism can also lead to language choice.

The family and interpersonal environment also affect the choice of vocabulary to a certain extent. According to Sun (2010), sexuality is the ratio of male and female features in discourse. There are a lot of male characteristics in the discourse, so the masculinity of the discourse is high, and vice versa. When people live in a more masculine environment, the degree of discourse tends to be masculine; on the contrary, it tends to be feminine.

Personal emotion is another vital factor, like answer (2). Emotional factors are mainly related to the speaker's emotional state of mind. When a person is excited, anxious or nervous, the expression of language will be greatly affected, giving rise to repetition or other verbal errors. In teaching, we also find that as learners answer questions or make speeches in class, the frequency of confusion between "he" and "she" is relatively high, which may be the result of anxiety and tension.

\section{Conclusion}

Through the research of the corpus, we know that the gender confusion of the third person singular pronouns by freshmen in English major is far more serious and regular in oral English. Both he/she and him/her are misused, and people are prone to use the third person positive pronoun and ignore the third person negative pronoun. Additionally, the actual error rate of the third person pronoun mixing should be higher than that reported here, because the texts which do not clearly reflect the antecedents is removed from the corpus in advance. In the research of the questionnaire, there are five factors that may contribute to the misuse of the pronoun "he" and "she", including mother tongue, attention distribution and working memory, pronunciation relationship, transfer of training, and social environment and personal factors. Among them, pronunciation relationship is the perspective that many scholars have not got involved with. Some of the responders point out that it is easy for them to confuse the pronunciation of he/she because the two hold some similarities in articulation to a certain degree, and also show differences in pronunciation. In the future, it is hopeful that we can check our findings from more levels of EFL and make a significant breakthrough in he/she pronoun research.

\section{References}

Antón-Méndez, I. (2010a). Gender bender: Gender errors in L2 pronoun production. Journal of Psycholinguistic 
Research, 39, 119-139. https://doi.org/10.1007/s10936-009-9129-z

Antón-Méndez, I. (2010b). Whose? L2-English speakers' possessive pronoun gender errors. Bilingualism: Language and Cognition, 13, 1-14. https://doi.org/10.1017/S1366728910000325

Chan, S. H., \& Wong, B. E. (2001). Understanding the Pronoun Paradigm in an L2 Context: The Malaysian Experience. Studies in Language and Language Teaching, 10, $25-37$.

Chen, L. (2013). Gender Misuse of Third Singular Pronouns of Different L1 EFL Learners in Oral Production - A Selective Fossilization Hypothesis Perspective. Master's thesis, Ocean University of China.

Clark, H. H., \& Sengul, C. J. (1979). In search of referents for nouns and pronouns. Memory \& Cognition, 7(1), 35-41. https://doi.org/10.3758/BF03196932

Dong, Y. P., \& Jia, T. T. (2011). Composition of preverbal message: Gender errors of English pronouns by Chinese learners of English. Modern Foreign Languages, 03, 279-286, 329.

Dong, Y. P., \& Li, Q. (2011). The Mixed Use of He/She for Chinese Learners of English. Foreign Language in China, 8(3), 22-29.

Jiang, Z. X. (2008). An Analysis of the Misuse of He and She. KAOSHI ZHOUKAN, 37, 221-222. https://doi.org/10.1097/MPA.0b013e3181619a45

Kamimura, T., \& Oi, K. (2001). The effects of differences in point of view on the story production of Japanese EFL students. Foreign Language Annals, 34(2), 118-128. https://doi.org/10.1111/j.1944-9720.2001.tb02817.x

Keating, P. A. (1991). Coronal places of articulation. In The special status of coronals: Internal and external evidence (pp. 29-48). Academic Press. https://doi.org/10.1016/B978-0-12-544966-3.50008-7

Levelt, W. J. M. (1989). Speaking: From Intention to Articulation. Cambridge, MA: MIT Press.

Pan, Xi. (2012). A brief discussion on the pronunciation characteristics and teaching of initial S, Sh and X. Jiannan Literature (Classic Teaching Center), 6, 92.

Sun, R. J. (2010). Sexism and gender difference in language. Huazhong University of Science and Technology Press.

Tao, W. H. (2003). Cognitive Analysis of Wrong Use of "He" or "She" in Oral English. Foreign Languages and Their Teaching, 2, 44-48.

Wei F. M. (2003). Re-discussion The Bottleneck The Zhuang Have in Speaking Putonghua_-Existing Problems and Solution. Journal of Guangxi University for Nationalities (Philosophy and Social Science Edition), 1, 91-96.

Yu, J. J., \& DEStech Publications Inc. (2015). Research on the Gender Discrimination Phenomenon and the Primary Cause in English and Chinese Language (pp. 919-923). 2015 2nd International Symposium on Engineering Technology, Education and Management (ISETEM 2015).

Zhao, J. (2011). Analysis of He/she Misuse in College Students' Oral English. Journal of Kaifeng Institute of Education, 01, 107-110.

Zheng, J. (2011). An Analysis of Fossilization in Chinese -English interlanguages from the Misuse of "he" and "she". Journal of Hebei Polytechnic University (Social Science Edition), 11(3), 143-145.

\section{Copyrights}

Copyright for this article is retained by the author, with first publication rights granted to the journal.

This is an open-access article distributed under the terms and conditions of the Creative Commons Attribution license (http://creativecommons.org/licenses/by/4.0/). 